\title{
An Impact of the Boost Diode Selection on the Overall Efficiency of Active Power Factor Correctors
}

\author{
Jan Moldaschl $1^{1}$, Jan Broulím ${ }^{2}$ \\ University of West Bohemia \\ UWB \\ Pilsen, The Czech Republic \\ moldy@kae.zcu.cz ${ }^{1}$, broulim@kae.zcu.cz ${ }^{2}$
}

\begin{abstract}
The paper focuses on a selection process of boost diodes for Active Power Factor Correctors (APFC) based on the Boost converter. The choice of the suitable boost diode plays crucial role for an efficiency of APFC. The main aim of the paper is devoted to theoretical and experimental comparison of the diodes. We have compared two ultra fast silicon diodes optimized for a Continuous Conduction Mode (CCM), soft-switching ultrafast rectifier and silicon carbide Schottky Barrier Diode (SBD). The experimental results show that the conduction losses are very similar but the switching losses are grossly different. In one case the diode optimized for softswitching was not able to properly operate above $200 \mathrm{~W}$ input power. It was caused likely due to the corrector works under CCM operation. Whereas, the SiC Schottky Barrier diodes are suitable for application in APFCs with high switching frequencies and working under CCM thanks to very small junction charge which is proved by this study.
\end{abstract}

Keywords-APFC; Active Power Factor Filters; CCM; Continuous Conduction Mode; SiC; Silicon Carbide Schottky Barrier Diodes

\section{INTRODUCTION}

In the last few years a growing interest has been devoted to Active Power Factor Correction Filters. APFC improvements play an important role. Current research on APFCs are focused on correction techniques and ways of the efficiency improvements. One of the first paper of the efficiency improvements is presented in [1]. The major drawback of this study is that it did not address to the switching frequency influence in detail. This paper focuses on performance various boost ${ }^{1}$ diodes working under CCM which is a common mode in APFCs. The instantaneous inductor current does not drop to zero within an one half period of the line voltage. This behavior, in other words hardswitching, requires very fast boost diodes. Regardless of this fact the mode has several advantageous properties which are smaller peak line current, smaller line current ripple, constant switching frequency and simplified design of the EMI filter associated with it. The waveform and basic schema (fig.1) depict a theory of operation. When the transistor is in the onstate, the inductor current goes up and an energy is stored in the inductor. When the transistor is open the inductor behaves like a voltage source which will

${ }^{1}$ the term of the boost diode was created due to its ability to raise the input voltage be summed with the line voltage. The result voltage opens the boost diode which conducts only in case that the output voltage is smaller than the input voltage. An average boost diode current is adequate to the load average current due to the charge through the diode equals to the bulk capacitor $\left(\mathrm{C}_{\text {out }}\right)$ charge and charge which the load $\left(\mathrm{R}_{\mathrm{L}}\right)$ consumes. This applies for diode which conducts the current. In case of the closure boost diode, the charge, which the load consumes, is pumped from the bulk capacitor. The principle of the operation is analogical to the conventional step-up converter although the control is more complex. It must provide the output voltage regulation as well as the shaping of the input current. A mathematical model is below:

$$
Z_{\text {in }}(s)=d^{\prime 2} R_{L} \frac{s^{2}\left(\frac{L_{1} C_{\text {out }}}{d^{\prime 2}}\right)+s \frac{\frac{L_{1}}{d^{\prime 2}}}{R_{L}}+1}{s R_{L} C_{\text {out }}+1}
$$

where $d^{\prime}=1-d ; d$ is switching duty ratio. The principle lies in the keeping of the input impedance to the constant value. As a result, the converter behaves analogical to the pure resistive load. In this paper, we explore the process of the boost diode selection and their influence on the overall efficiency. The remainder of the paper is organized as follows: Section II. discuss about properties comparison between different types of the power diodes. The measurements are presented in Section III. Section IV. is devoted to a discussion about the obtained results. The conclusion is reported in Section V.

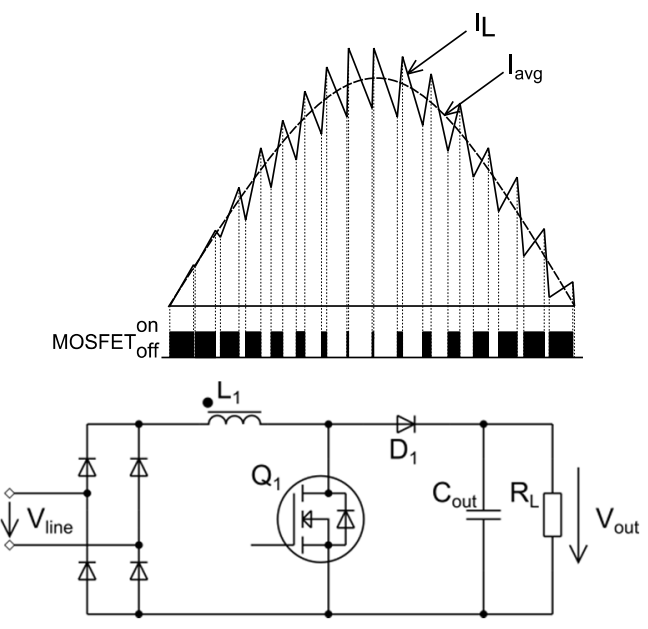

Fig. 1 CCM waveform and Basic Schema 


\section{BOOST DIODES COMPARISON}

\section{A. Diodes Properties}

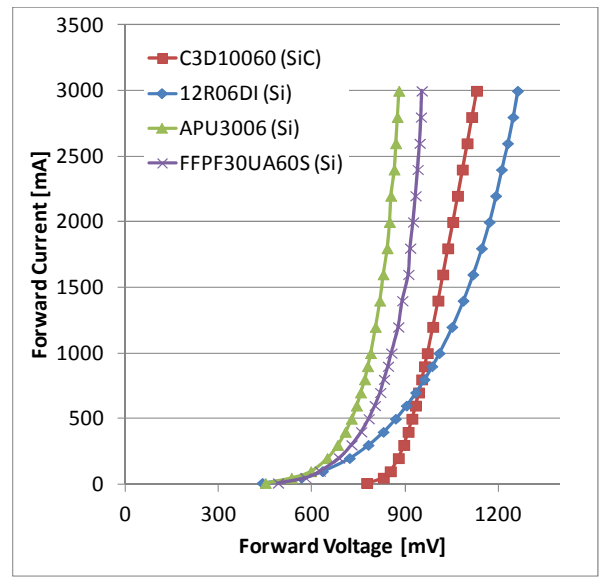

Fig. 1 Forward Current vs. Forward Voltage

APFCs based on the boost converter are usually designed for a high output voltage. The switching frequency of the commercial APFCs are frequently around $60 \mathrm{kHz}$. The shrinking trends force producers to develop APFCs with switching frequencies over $200 \mathrm{kHz}$. This application requires fast switching diodes with low reverse recovery charge and high blocking voltage. Schottky diodes based on the silicon substrate reach maximal $250 \mathrm{~V}$ blocking voltage therefore they are not suitable for this application. For this application are usually used ultrafast silicon PIN diodes. Unlikely, these diodes are characterized by worse dynamic parameters than silicon Schottky diodes and their forward voltages are large. A silicon carbide substrate offers excellent thermal conductance, high breakdown electric field, and wide band gap.

In the PIN Ultra fast Si Diodes, the diode structure is organized as a sandwich structure with very poorly doped semiconductor region between a p-type semiconductor and an n-type semiconductor regions. The heavily doped regions allow construct ohmic contacts. The thickness of the poorly doped region affects a maximal reverse voltage of the diodes. Unfortunately, on-state resistance and reverse recovery charge grow hand in hand with the thickness of the intrinsic region. Advantage of the PIN diodes is their low leakage current. The leakage current strongly depends on the die temperature.

Due to the high leakage current of the pure $\mathrm{Si}$ Schottky diodes they can be apply up to $250 \mathrm{~V}$ reverse

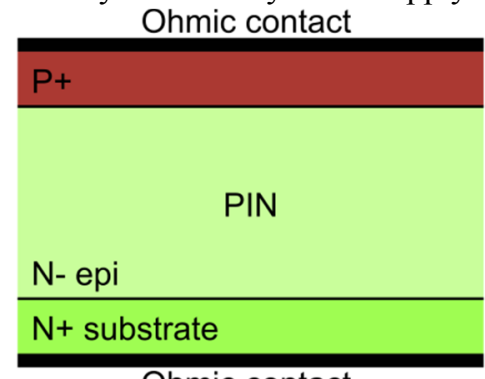

Ohmic contact

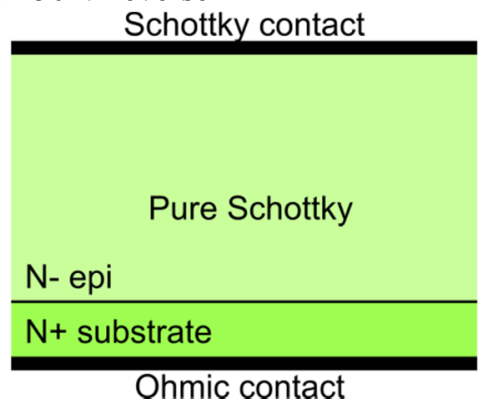

Ohmic contact voltage. The Schottky barrier is created by merger of the metal contact and the n-type region. The structure is shown on the picture $3 \mathrm{~b}$. These diodes have extraordinary dynamic features and low forward voltage drop.

Owing to very low intrinsic concentration of carriers in the $\mathrm{SiC}$ substrate, silicon carbide devices allow operate under high temperature conditions (experimentally up to $600^{\circ} \mathrm{C}$, theoretically up to $800^{\circ} \mathrm{C}$ ) but current polymer packages are not able to overcome the $200^{\circ} \mathrm{C}$ temperature. This situation may be changed by Ceramic packages called LTCC (Low Temperature Co-fired Ceramic) in the future. The excellent thermal conductivity of the substrate improves the heat transfer to the case. The high breakdown electric field strength of the $\mathrm{SiC}$ substrate opens a possibility of the construction of the high voltage diodes with a flat profile.

The main benefit of the SiC Schottky Barrier Diodes is excellent dynamic performance and mainly their negligible thermal drift. SiC SBDs have the ultra low junction charge Qc. Thanks to this fact the switching losses are significantly suppressed.

Combination of the pure Schottky and PIN diode structures brings forth Junction Schottky Barrier Diodes. The structure on the picture (fig. 3c) creates an adding of the p-type wells into n-type semiconductor of the "pure Schottky diode structure".

The hybrid structure obtains the forward properties of the pure Schottky diodes and reverse characteristics of the PIN diodes. Consequently, the structure behaves like pure Schottky diodes when the forward voltage is present and like PIN diodes when the reverse voltage is present. Thanks to this, the structure has low forward voltage drop and very low total junction charge Qc. Detail of phenomenon at the reverse voltage is on the figure (fig. 4). The presence of depletion regions around p-type wells considerably reduces the leakage current.

The application of the SiC Schottky Barrier Diodes in the APFC operates under CCM leads to increasing of the efficiency regardless of the growing switching frequency which allow shrink the passive components of APFCs. Consequently, total costs of the APFC with SiC Schottky diodes can be similar maybe even lower. They have high voltage blocking capability and low leakage current. A crucial advantage is that the parameters are almost independent on the steepness of the forward current and the temperature of the die.

Fig. 2 Structural Layout of Diodes, a) PIN Ultra Fast Diode, b) Pure Schottky, c) Junction Barrier Schottky 


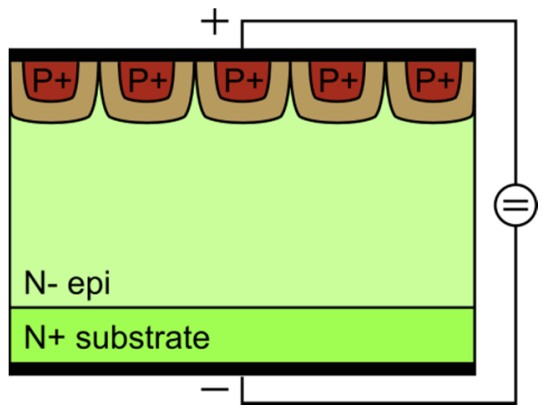

Fig. 3 Junction Barrier Schottky under Reverse Voltage

Junction Schottky Barrier Diodes merge advantageous properties of both PIN and pure Schottky structures. Junction Schottky Barrier Diodes based on the $\mathrm{SiC}$ substrate are suitable for high voltage and high switching frequency. The worthwhile application sectors are several. One feasible application can be APFCs with high output voltage $(400 \mathrm{~V})$ and switching frequencies above $200 \mathrm{kHz}$.

\section{B. Conduction losses}

Conduction losses depend on the forward voltage drop and the forward current. These losses can be computed by following expression.

$$
P_{d_{-} \text {cond }}=I_{\text {out }} \cdot V_{F}
$$

Where $\mathrm{I}_{\text {out }}$ is the output current, which is adequate to the average diode current; $\mathrm{V}_{\mathrm{F}}$ is the forward voltage drop. Specifically for the C3D10060 (SiC) at 230VAC input voltage, 400VDC output voltage and $500 \mathrm{~W}$ output power thus output current is $1.25 \mathrm{~A}$. The computation gives the most accurate estimation of the losses. Any other estimation based on the power loss integration are not so suitable owing to the variable duty ratio within one half cycle period of the $\mathrm{AC}$ line.

$$
P_{d_{-} \text {cond }}=1.25 \cdot 1.006=1.2575 \mathrm{~W}
$$

Similarly for next diodes 12R06DI (4), APU3006 (5) and FFPF30UA60S (6)

$$
\begin{aligned}
& P_{d_{-} \text {cond }}=1.25 \cdot 1.088=1.36 \mathrm{~W} \\
& P_{d_{-} \text {cond }}=1.25 \cdot 0.82=1.025 \mathrm{~W} \\
& P_{d_{-} \text {cond }}=1.25 \cdot 0.892=1.115 \mathrm{~W}
\end{aligned}
$$

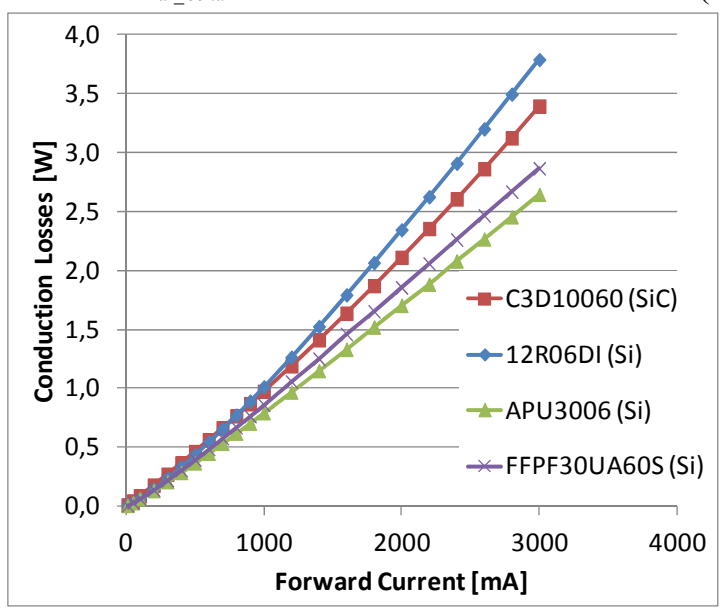

Fig. 4 Conduction Losses Comparison

\section{Switching losses}

Equation (7) represents the switching losses in the diodes. Where $\mathrm{Q}_{\mathrm{Ir}}$ is reverse recovery charge, $\mathrm{V}_{\text {out }}$ is output voltage and $\mathrm{f}_{\mathrm{sw}}$ is switching frequency.

$$
\begin{gathered}
P_{d_{-} s w}=0.5 \cdot Q_{r r} \cdot V_{\text {out }} \cdot f_{\text {sw }} \\
P_{d_{-} s w}=0.5 \cdot 25 \cdot 10^{-9} \cdot 400 \cdot 2 \cdot 10^{5}=1 \mathrm{~W} \\
P_{d_{-} s w}=0.5 \cdot 180 \cdot 10^{-9} \cdot 400 \cdot 2 \cdot 10^{5}=7.2 \mathrm{~W} \\
P_{d_{-} s w}=0.5 \cdot 580 \cdot 10^{-9} \cdot 400 \cdot 2 \cdot 10^{5}=23.2 \mathrm{~W} \\
P_{d_{-} s w}=0.5 \cdot 360 \cdot 10^{-9} \cdot 400 \cdot 2 \cdot 10^{5}=14.4 \mathrm{~W}
\end{gathered}
$$

Total losses can be acquired by sum of conduction and switching losses.

$$
\begin{gathered}
P_{\text {total }}=P_{d_{-} \text {cond }}+P_{d_{-} s w}=2.2575 \mathrm{~W} \\
P_{\text {total }}=P_{d_{-} \text {cond }}+P_{d_{-} s w}=8.56 \mathrm{~W} \\
P_{\text {total }}=P_{d_{-} \text {cond }}+P_{d_{-} s w}=24.225 \mathrm{~W} \\
P_{\text {total }}=P_{d_{-} \text {cond }}+P_{d_{-} s w}=15.515 \mathrm{~W}
\end{gathered}
$$

TABLE I. DIODE PARAMETERS

\begin{tabular}{|c|c|c|c|c|}
\hline & C3D10060 & 12R06DI & APU3006 & FFPF30UA60S \\
\hline $\mathrm{V}_{\mathrm{R}}[\mathrm{V}]$ & 600 & 600 & 600 & 600 \\
\hline $\mathrm{I}_{\mathrm{F}}[\mathrm{A}]$ & 10 & 7 & 30 & 30 \\
\hline $\begin{array}{c}\mathrm{Q}_{\mathrm{rr}} / \mathrm{Q}_{\mathrm{c}} \\
{[\mathrm{nC}]}\end{array}$ & 25 & 180 & 580 & 360 \\
\hline
\end{tabular}

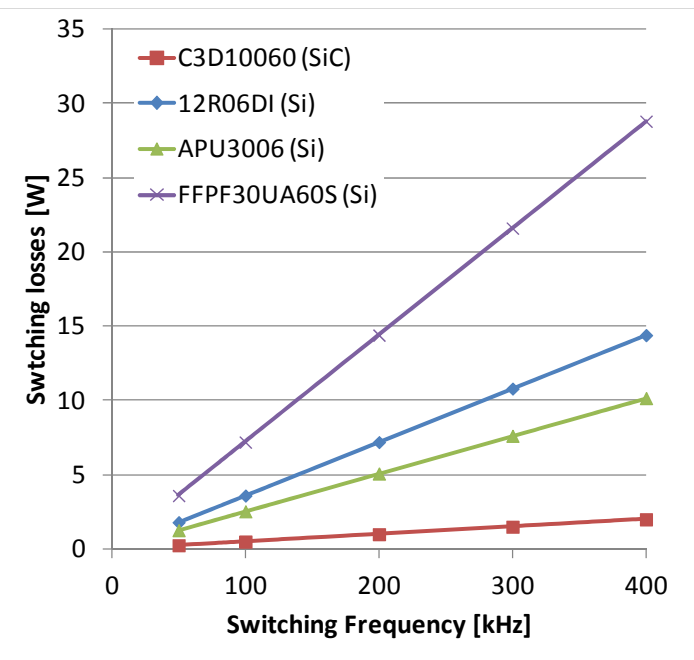

Fig. 5 Switching Losses Comparison

\section{EXPERIMENTAL RESULTS}

Measurement were carried out on two different APFCs. Both of them worked under CCM. First APFC uses UCC28180 control circuit and their switching frequency is $200 \mathrm{kHz}$. Second APFC is controlled by UCC28019. The switching frequency of this circuit is fixed $65 \mathrm{kHz}$. The selected diodes for the measurements are shown in the table 1. These diodes were deliberately chosen due to their different parameters. The C3D10060 diode is SiC Schottky Barrier Diode. Two diodes (12R06DI and FFPF30UA60S) are ultra fast diodes suitable for hardswitching and for APFCs. Last diode (type APU3006) is soft-switching ultrafast rectifier optimized for APFCs worked under discontinuous or critical 
conduction mode. APFCs were powered by galvanic isolated variable transformer. An input voltage was kept at $230 \mathrm{~V}$. The measured data demonstrate that the diode selection plays crucial role in case that the switching frequency is more than $200 \mathrm{kHz}$. The diode selection for lower frequencies up to $100 \mathrm{kHz}$ is advisable to select mainly by costs of the diodes due to negligible dependence on the overall performance.

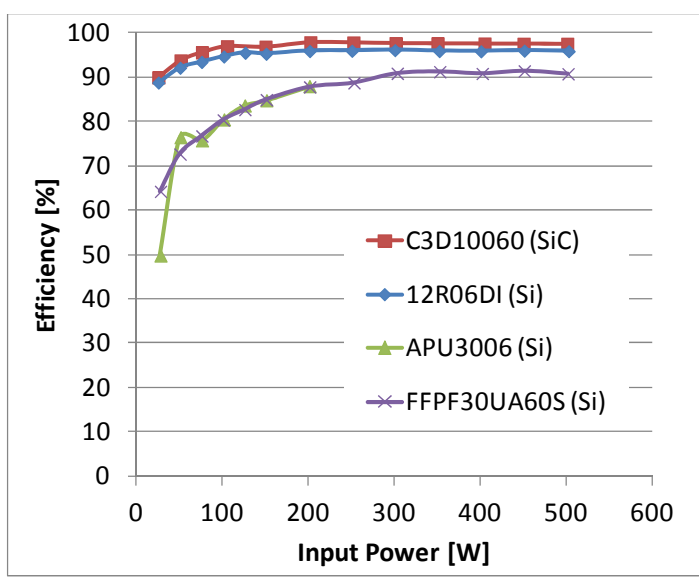

Fig. 6 Efficiency Comparison $(200 \mathrm{kHz})$

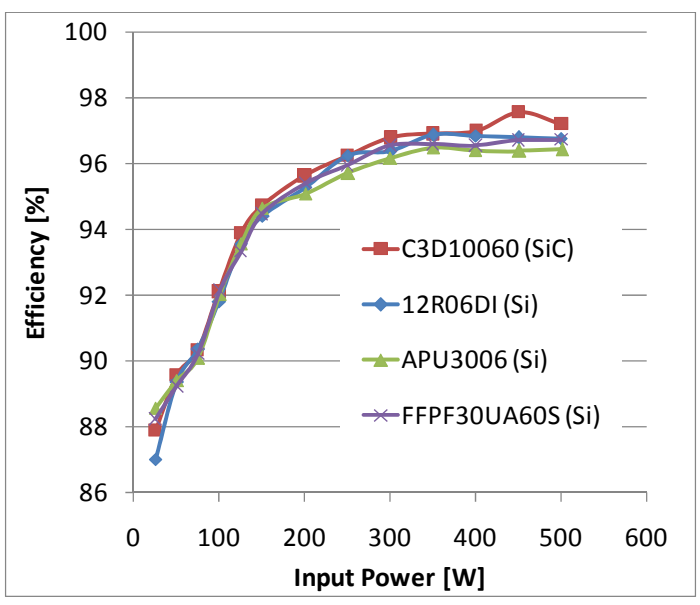

Fig. 7 Efficiency comparison $(65 \mathrm{kHz})$

\section{DISCUSSION}

In this paper we examined the influence of the boost diode selection on the APFCs overall efficiency. This study demonstrates advantages of SiC Schottky Barrier Diodes against ultra fast Si diodes. The main finding of this study is that the SiC Schottky Barrier Diodes are preferred for switching frequencies exceeding $200 \mathrm{kHz}$. The ultra fast diode optimized for soft-switching was failed during the test due to this diode type is not applicable in the APFC with CCM. The experiment simultaneously shows that the $\mathrm{SiC}$ diode application in the APFCs with frequencies up to $100 \mathrm{kHz}$ is unfounded. All results are summarized in the graphs (fig. 7 and fig. 8) and in the table below.

\section{TABLE II. EXPERIMENTAL RESULTS COMPARISON}

\begin{tabular}{|l|c|c|c|}
\hline \multirow{2}{*}{$70 \mathrm{kHz}$} & \multicolumn{3}{|c|}{ Experimental results of another study [1] } \\
\cline { 2 - 4 } & RURD460 & STTH5R06D & SDP04S60 \\
\hline $\begin{array}{l}\text { Output } \\
\text { power [W] }\end{array}$ & 298 & 300 & 300 \\
\hline
\end{tabular}

\begin{tabular}{|c|c|c|c|c|}
\hline \multirow{2}{*}{$70 \mathrm{kHz}$} & \multicolumn{4}{|c|}{ Experimental results of another study [1] } \\
\hline & RURD460 & $S T$ & I5R06D & SDP04S60 \\
\hline $\begin{array}{l}\text { Efficiency } \\
{[\%]}\end{array}$ & 95.5 & & 6.4 & 97 \\
\hline \multirow{2}{*}{$200 \mathrm{kHz}$} & \multicolumn{4}{|c|}{ Experimental results of our study } \\
\hline & $C 3 D 10060$ & 12R06DI & APU3006 & FFPF30 \\
\hline $\begin{array}{l}\text { Output } \\
\text { power [W] }\end{array}$ & 294 & 288 & * & 275 \\
\hline $\begin{array}{l}\text { Efficiency } \\
{[\%]}\end{array}$ & 97.7 & 96.1 & * & 90.8 \\
\hline $65 \mathrm{kHz}$ & \multicolumn{4}{|c|}{$*$ measured process failed } \\
\hline $\begin{array}{l}\text { Output } \\
\text { power [W] }\end{array}$ & 291 & 290 & 289 & 290 \\
\hline $\begin{array}{l}\text { Efficiency } \\
{[\%]}\end{array}$ & 96.8 & 96.4 & 96.2 & 96.5 \\
\hline
\end{tabular}

\section{CONCLUSION}

From the outcome of our investigation it is possible to conclude that the SiC Schottky Barrier Diodes can improve the efficiency of the APFC working with high switching frequencies. Although, these diodes improve a performance at lower frequencies their use due to higher costs are not profitable. The obtained data show that the diodes optimized for soft-switching are not appropriate for hard-switching application. A future work will involve a inductor design focusing on the increasing efficiency.

\section{ACKNOWLEDGMENT}

This research has been supported by the program Student Grant System, project no. SGS 2015-002 'Modern methods in solution, design and application of electronic and communication systems'.

\section{REFERENCES}

[1] SPIAZZI, G., S. BUSO, M. CITRON, M. CORRADIN a R. PIEROBON. Performance evaluation of a schottky SiC power diode in a boost PFC application. IEEE Transactions on Power Electronics. 2003, vol. 18, issue 6, s. 1249-1253. DOI: 10.1109/tpel.2003.818821.

[2] CREE. Selection Guide of SiC Schottky Diode in CCM PFC Application. [online]. 2012 [2015-04-02]. Available from: http://goo.gl/784xn8

[3] HODGE, Stuart. SiC Schottky Diodes in Power Factor Correction. [online]. 2004, p. 4 [2015-04-02]. Available from: http://goo.gl/cx0LaU

[4] MIESNER, Christian, Roland RUPP, Holger KAPELS, Michael KRACH a Ilia ZVEREV. ThinQ! Silicon Carbide Schottky Diodes: An SMPS Circuit Designer's Dream Comes True. ThinQ! Silicon Carbide Schottky Diodes: An SMPS Circuit Designer's Dream Comes True [online]. p. 4 [201504-02]. Available from: https://goo.gl/QWKL2r

[5] SINGH, Ranbir a James RICHMOND. SiC Power Schottky Diodes in Power Factor Correction Circuits. SiC Power Schottky Diodes in Power Factor Correction Circuits [online]. 2006, p. 7 [2015-04-02]. Available from: http://goo.gl/kxz0er

[6] AGARWAL, Anant, Ranbir SINGH, Sei-Hyung RYU, James RICHMOND, Craig CAPELL, Scott SCHWAB, Brice MOORE a John PALMOUR. $600 \mathrm{~V}, 1$ - 40 A, Schottky Diodes in SiC and Their Application. [online]. p. 9 [2015-0402]. Available from: http://goo.gl/IEkl5d

[7] KŘEČEK, Tomáš. VŠB-TU OSTRAVA. Součástky na bázi $\mathrm{SiC}$ [online]. p. 8 [2015-04-02]. Available from: http://www.roznovskastredni.cz/dwnl/pel2007/03/Krecek.pdf

[8] DAHLQUIST, Fanny. Junction Barrier Schottky Rectifiers in Silicon Carbide [online]. Kista, 2002 [2015-04-02]. ISBN 1650-8599. Available from: http://goo.gl/P8KbDd 